\title{
Pain in Children with Juvenile Rheumatoid Arthritis: A Descriptive Study
}

\author{
HUDA HUIJER ABU-SAAD AND MIR UITERWIJK \\ Department of Nursing Science, University of Limburg, Maastricht, The Netherlands
}

\begin{abstract}
The purpose of this study is to describe the pain experienced by children with juvenile rheumatoid arthritis. A patient sample composed of 33 children, 7-16 y of age, with juvenile rheumatoid arthritis was included in the study. The children, their parents, and the attending rheumatologist assessed the child's pain using the Abu-Saad pediatric pain assessment tool. In addition, a disease activity index was used by the physician. All children reported pain. This was most often described as hurting, stinging, warm, and uncomfortable. Significant correlations were found for present pain between the child, parent, and physician.
\end{abstract}

ABSTRACT

Pain in children is a complex phenomenon involving a number of components that interact to influence how a child perceives, experiences, and responds to pain. In the assessment and management of pain, it is essential to distinguish among acute, chronic, and recurrent pain episodes in children $(1,2)$. Acute pain is characterized by its signal function which warns the individual to seek rest or immediate relief. It is often the intensity of acute pain and the associated anxiety that distinguish it from chronic pain. Chronic pain, on the other hand, is not only associated with an anxious component but with a constellation of reactive features which are maintained independently even in the absence of tissue damage or injury (1). Recurrent pain is episodical in nature and is usually associated with noxious stimuli. Pain related to juvenile rheumatoid arthritis corresponds to the chronic pain model described above.

In contrast to the extensive literature on adult chronic pain assessment and management, the systematic investigation of chronic and recurrent pain in children is still relatively a young area of inquiry. A number of investigators $(3,4)$ studied the pain intensity in subjects with arthritis and concluded that children with juvenile rheumatoid arthritis experience less pain than adults. Beales et al. (5) on the other hand showed that older children with juvenile rheumatoid arthritis (12-17 y of age) tended to report higher levels of pain than younger children (6-11 y of age). The authors concluded that with

Received July 18, 1994; acceptcd January 30, 1995

Correspondence: Prof. Dr. H. Huijer Abu-Saad, R.N., Ph.D., Department of Nursing Science, University of Limburg, Postbus 616, 6200 M.D. Maastricht, The Netherlands.
The worst pain of the child for the previous week, and not the present pain, correlated with the disease activity as rated by the physician. These findings indicate a need for pain assessment in patients with juvenile rheumatoid arthritis and emphasize the importance of longitudinal studies in this area. (Pediatr Res 38: 194-197, 1995)

\section{Abbreviations}

PPQ, Pediatric Pain Questionnaire

PPAT, Pediatric Pain Assessment Tool increasing age children's understanding and conceptualization of illness and disease become greater.

Thompson and Varni (6) developed the PPQ which is modeled after the McGill pain questionnaire but designed to be sensitive to the cognitive-developmental conceptualizations of children. Thus far, the PPQ has been tested with juvenile rheumatoid arthritis and sickle cell disease, and as a result data are emerging on its psychometric properties and clinical utility (7-9). In a study of chronic musculoskeletal pain in juvenile rheumatoid arthritis by Varni et al. (10) using the PPQ, the report of pain by the child on the visual analog scale correlated highly with both the parent's $(r=0.72, p<0.001)$ and the physician's $(r=0.65, p<0.001)$ ratings.

Ilowite et al. (11) studied the relationship between pain and joint inflammation in patients with juvenile rheumatoid arthritis using the PPQ and thermography. Correlations of patients' pain intensity ratings and joint inflammation were found to be significant only with children younger than $7 \mathrm{y}$ of age. The lack of relationship with children older than $7 \mathrm{y}$, according to the authors, may be due to the increased number of socioemotional factors in this age group affecting pain perception and consequently pain response.

In examining the literature on the assessment of chronic pain in children, it becomes evident that a great deal of emphasis is placed not only on the accuracy of the methods used but also on the factors affecting the pain experience (12). One of these factors that has received very little attention in scientific research is the pain threshold. Walco et al. (8) investigated the relationship between the pain threshold levels and clinical pain in four groups of children between 5 and $16 \mathrm{y}$ of age. The 
children studied included those with juvenile rheumatoid arthritis, sickle cell disease, and asthma, along with healthy controls. Walco and colleagues found that children with juvenile rheumatoid arthritis and sickle cell disease had significantly lower pain thresholds than did their healthy peers. The authors concluded that the experience of recurrent pain may sensitize children to future pain stimulation.

In describing the factors influencing the pain experience, Varni et al. (13) developed an empirical model to predict pain perception and functional status in children with juvenile rheumatoid arthritis. The predictor variables in the model included the child psychologic adjustment, family psychosocial environment, and disease parameters as well as the worst pain for the previous week. Their results emphasize the importance of a multidimensional approach for assessing chronic pain in children. Savedra et al. (14) have similarly developed a multidimensional method for assessing pain in children which is currently undergoing further psychometric testing.

A major disadvantage of the above-mentioned methods is their strong linguistic tie and their cultural orientation. For adult chronic pain patients, the most commonly used and tested assessment tool is the McGill Pain Questionnaire (15). This tool has been translated and tested for use in the Netherlands. Due to the absence of a pain assessment tool for children in the Netherlands, Abu-Saad developed and tested the PPAT (1620). This tool is modeled after the McGill Pain Questionnaire and the PPQ and is designed to be culturally and developmentally sensitive, with forms for child, parent, physician, and nurse. The child form addresses the intensity of pain, the sensory and affective/evaluative qualities of pain, coping strategies when in pain, and the influence of pain on activities of daily living. The PPAT was rigorously tested in a number of studies and was proven to be valid and reliable for use with children. The purpose of this study is to describe, using the PPAT, the pain experienced by children with juvenile rheumatoid arthritis.

\section{METHODS}

\section{Subjects}

The subjects were 33 children, 7-16 y of age, with juvenile rheumatoid arthritis receiving treatment at the outpatient departments of two academic teaching hospitals in the Netherlands. Of the 33 children 15 suffered from polyarticular arthritis, eight from pauciarticular arthritis, and 10 had a systemic onset. The sample consisted of 24 girls and 9 boys. All children, with the exception of two, were of Dutch origin.

\section{Procedure}

The parents of the children identified as possible candidates were approached by the researcher and the child rheumatologists and invited to participate. All parents signed an informed consent form before actual participation. The study was approved by the ethics and scientific committees of both hospitals. Approval was also sought from all attending physicians, residents, and staff of the respective units. Data collection took place in an examining room of the out-patient clinic.

\section{Instruments}

The Abu-Saad PPAT. The PPAT child version was administered in a structured interview format after the child's physical examination by the pediatric rheumatologist. The parent filled out the form when the child was interviewed by the researcher. The physician rated present pain on a $10-\mathrm{cm}$ scale at the end of the physical examination. The nurses version of the tool was not used because nurses were not directly involved in the care of juvenile rheumatoid arthritis patients on the out-patient unit.

All pain ratings were made separately by the child, parent, and rheumatologist. The child and parent versions are very similar. The PPAT consists of 32 word descriptors, a $10-\mathrm{cm}$ visual analog scale measuring present and worst pain (Fig. 1), coping strategies used when in pain, and the influence of pain on the activities of daily living.

Disease activity index. Similar to that used in the work of Varni et al. (10), a disease index was used to provide a global assessment of the disease activity. The assessment was provided by the rheumatologist at the end of the physical examination and included the categories severe, moderate, mild, quiescent (no physical or laboratory signs, on medication), and remission (quiescent for 2 mo without medication). This global assessment of disease activity has been chosen because it is less invasive and is commonly used by rheumatologists (6).

\section{RESULTS}

Pain quality. Table 1 lists the most frequently chosen pain descriptors used by the children and their parents and analyzed as a function of age (7-11 and 12-16). Two categories of word descriptors are used in this study, sensory and affective/ evaluative, which are based on the work of Abu-Saad et al. (18).

Children with juvenile rheumatoid arthritis use most frequently $(50 \%)$ the words hurting, stinging, warm, and uncomfortable to describe their pain. Almost $30 \%$ of the children used the words fearful, whining, and tiring. Words that were almost never used included shooting, beating, pinching, pulling, cold, pumping, sickening, sharp, pounding, and miserable.

Pain descriptors which were similarly used by children and their parents included warm, stinging, tingling, tiring, sickening, miserable, and unbearable.

Using Mann-Whitney U, no significant difference was found between children 7-11 y and 12-16 y in their use of word descriptors in the sensory and affective/evaluative domains.

Pain intensity. Table 2 shows the intensity scores of child, parent, and physician.

Using Mann Whitney $U$, no significant differences were found in gender and between children 7-11 y and 12-16 y of age in their use of the $10-\mathrm{cm}$ scale.

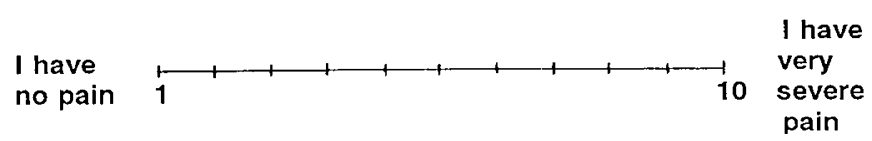

Figure 1. The $10-\mathrm{cm}$ scale. pain 
Table 1. Pain descriptors most frequently chosen

\begin{tabular}{|c|c|c|c|c|c|}
\hline & \multicolumn{3}{|c|}{ Child } & \multirow[b]{2}{*}{ Parent } & \multirow{2}{*}{$\begin{array}{l}\text { Agreement } \\
\text { child/paren }\end{array}$} \\
\hline & Total & $7-11 y$ & $12-17 y$ & & \\
\hline \multicolumn{6}{|l|}{ Sensory } \\
\hline Hurting & 23 & 9 & 14 & 6 & 6 \\
\hline Stinging & 18 & 6 & 12 & 13 & 10 \\
\hline Warm & 14 & 6 & 8 & 13 & 7 \\
\hline \multicolumn{6}{|l|}{ Affective/evaluative } \\
\hline Uncomfortable & 16 & 6 & 10 & 6 & 5 \\
\hline Fearful & 11 & 7 & 4 & 2 & 1 \\
\hline Whining & 11 & 3 & 8 & 9 & 4 \\
\hline Tiring & 10 & 4 & 6 & 17 & 6 \\
\hline
\end{tabular}

Table 2. Present and worst pain intensity on the 10-cm scale

\begin{tabular}{lcccccc} 
& \multicolumn{3}{c}{ Present pain } & & \multicolumn{2}{c}{ Worst pain } \\
\cline { 3 - 4 } \cline { 7 - 8 } & Child & Parent & Physician & & Child & Parent \\
\hline Mean & 1.07 & 1.51 & 2.77 & & 3.72 & 2.62 \\
Range & $0-5.5$ & $0-10$ & $0-9.5$ & & $0-9.5$ & $0-7.5$ \\
\hline
\end{tabular}

Table 3 presents the Spearman Rank Order correlation coefficients between the child, parent, and physician ratings on the $10-\mathrm{cm}$ scale. Correlations between child, parent, and physician were found to be significant with the exception of one, the mother's and physician's assessment of present pain.

Disease activity index. Table 4 shows the child and physician mean pain scores per category of the disease activity index. Children rated by their physician to have a mild disease activity have used, strangely enough, the highest scores to rate their present pain followed by children in the quiescent phase of their illness. Physicians pain ratings of children in stage 1 of the disease was the highest followed by stage 3 and then stage 2 .

The worst pain reported by the child can be seen in stage 2 of the disease followed by stages $1,3,4$, and 5, respectively. In other words, as the physician-rated disease activity increased, there was an almost corresponding increase in the child-rated worst pain intensity for the previous week.

Coping with pain. Children use different strategies to cope with pain. Some of the most frequently used strategies are listed in Table 5.

Pain and activities of daily living. Table 6 lists the activities which appeared to be the most influenced by pain as reported by the child. Pain does not appear to influence the child's reading, TV watching, and eating patterns.

Table 3. Spearman Rank Order correlation coefficients between pain ratings on the $10-\mathrm{cm}$ scale

\begin{tabular}{llllll}
\hline & \multicolumn{2}{c}{ Child } & & \multicolumn{2}{c}{ Parent } \\
\cline { 2 - 3 } & $\begin{array}{c}\text { Present } \\
\text { pain }\end{array}$ & $\begin{array}{c}\text { Worst } \\
\text { pain }\end{array}$ & & $\begin{array}{c}\text { Present } \\
\text { pain }\end{array}$ & $\begin{array}{c}\text { Worst } \\
\text { pain }\end{array}$ \\
\hline Worst pain, child & $0.50^{* *}$ & & & \\
Present pain, parent & $0.53^{* * *}$ & $0.50^{* *}$ & & \\
Worst pain, parent & $0.40^{* *}$ & $0.77^{* *}$ & $0.46^{* *}$ & \\
Present pain, physician & $0.32^{* *}$ & $0.43^{* *}$ & 0.10 & $0.60^{* * *}$ \\
\hline$* p<0.10$. & & & & & \\
$* * p<0.05$. & & & & & \\
$* * * p<0.001$. & & & &
\end{tabular}

Table 4. Mean pain scores per disease activity index (child and physician)

\begin{tabular}{cccc}
\hline & \multicolumn{2}{c}{ Present pain } & \\
\cline { 2 - 3 } Disease stages & $\begin{array}{c}\text { Child } \\
\text { [mean (SD)] }\end{array}$ & $\begin{array}{c}\text { Physician } \\
\text { [mean (SD)] }\end{array}$ & $\begin{array}{c}\text { Worst pain: child, } \\
\text { [mean (SD)] }\end{array}$ \\
\hline Severe & 0.00 & 7.25 & 4.50 \\
& $(0.00)$ & $(1.50)$ & $(3.02)$ \\
Moderate & 0.87 & 2.81 & 4.81 \\
& $(1.64)$ & $(2.32)$ & $(3.02)$ \\
Mild & 1.68 & 3.10 & 3.90 \\
& $(1.76)$ & $(1.07)$ & $(3.69)$ \\
Quiescent & 1.19 & 0.75 & 2.81 \\
& $(2.03)$ & $(1.00)$ & $(3.09)$ \\
Remission & 0.00 & 0.00 & 0.50 \\
& $(0.00)$ & $(0.00)$ & $(0.70)$ \\
\hline
\end{tabular}

Table 5. Frequency of coping strategies used when in pain

\begin{tabular}{lc}
\multicolumn{1}{c}{$(n=33)$} \\
\hline \multicolumn{1}{c}{ Strategy } & Score \\
\hline Rest & 12 \\
Seek distraction & 10 \\
Watch TV & 6 \\
Read & 4 \\
Avoid joint exertion & 4 \\
Support joint & 4 \\
Call mother & 4 \\
Use warm or cold compressors & 3 \\
Use medicine & 3 \\
Use exercise & 2 \\
Use massage & \\
\hline
\end{tabular}

Table 6. Activities of daily living most influenced by pain $(n=33)$

\begin{tabular}{lc}
\hline Activity & Score \\
\hline Sport & 27 \\
Friends & 18 \\
Sleep & 17 \\
Schoolwork & 14 \\
\hline
\end{tabular}

\section{DISCUSSION}

Children 7-16 y of age with juvenile rheumatoid arthritis had no difficulty using the PPAT to describe their pain. The pain word descriptors most frequently chosen by the children to describe their arthritis pain include hurting, stinging, warm, and uncomfortable. These words represent the sensory and affective/evaluative categories of pain and depict sensations most frequently associated with arthritis pain. No significant difference was found in the use of word descriptors and the $10-\mathrm{cm}$ scale between children 7-11 y and 12-16 y of age. These pain descriptor terms begin the process of differentiating the qualities of arthritic pain as experienced by children in the Netherlands. These results are interestingly enough comparable to the results of Varni et al. (10) and Vandvik and Eckblad (21) whose studies depict similar use of word descriptors.

Significant correlations were found on the $10-\mathrm{cm}$ scale for present pain between the child, parent, and physician. This is in accordance with the results reported by Varni et al. (10) who found significant correlations for present pain between child, parent, and physician $(p<0.001)$. A higher correlation was also found between the present pain as reported by the physician and the worst pain for the previous week as reported by 
the child. The child's present pain was assessed in a quiet room when the child was resting and as such experiencing no pain. The physician's pain assessment, on the other hand, took place directly after the physical examination when the child's joints are usually manipulated, thus causing more pain. Because arthritis pain is usually more severe when the child is in motion, the assessment of worst pain for the previous week presents in our view a better indication of the child's pain than present pain.

The same arguments apply when explaining the significant correlation between the disease activity index and the child's worst pain for the previous week. Interestingly enough, Vandvik and Eckblad (21) found also no significant correlations between actual pain intensity and disease severity as assessed by the physician. These results emphasize the importance of assessing, in addition to present pain, the worst pain as experienced by the child during the last week. Rapoff et al. (22) studied the validity and reliability of parental ratings of morning stiffness, activity limitations, and pain complaints on a sample of 31 juvenile rheumatoid arthritis patients. They found parental ratings to be significant predictors of active joint counts and concluded that these ratings are valid and moderately reliable measures of disease activity in juvenile rheumatoid arthritis.

These findings indicate a need for ongoing pain assessment in juvenile rheumatoid arthritis. They also speak to the importance of assessing the child's worst pain for the previous week and using it as an indication when determining pain interventions. The correlation between the disease activity and the child's worst pain partially supports the construct validity of the $10-\mathrm{cm}$ scale. Finally, the PPAT provided information regarding coping strategies that arthritis children most frequently use when in pain such as resting and seeking distraction from pain and sheds light on how pain influences their day-to-day functioning. Longitudinal studies are nevertheless needed to address the multidimensional aspects of pain and the influence of pain on the daily functioning of the child with juvenile rheumatoid arthritis. Studies addressing coping style, locus of control, family involvement as well as symptomatology are important in furthering our knowledge in this area. Further research is here warranted.

\section{REFERENCES}

1. McGrath, PA 1987 The multidimensional assessment and management of recurrent pain syndromes in children. Behav Res Ther 25:251-262

2. Varni, JW 1983 Clinical Behavioral Pediatrics: An Interdisciplinary Biobehavioral Approach. Pergamon Press, New York

3. Laaksonen, AL, Laine, V 1961 A comparative study of joint pain in adult juvenile rheumatoid arthritis. Ann Rheum Dis 20:386-387

4. Scott, PJ, Ansell, BM, Huskisson, EC 1977 Measurement of pain in juvenile polyarthritis. Ann Rheum Dis 36:186-187

5. Beales, JG, Keen, JH, Holt, PJL 1983 The child's perception of the disease and experience of pain in juvenile chronic arthritis. J Rheumatol 10:61-65

6. Thompson, KL, Varni, JW 1986 A developmental cognitive-biobehavioral approach to pediatric pain assessment. Pain 25:282-296

7. Thompson, KL, Varni, JW, Hanson, V 1987 Comprehensive assessment of pain in juvenile rheumatoid arthritis: an empirical model. J Pediatr Psychol 12:241-255.

8. Walco, GA, Dampier, CD, Harstein, G Djordjevic, D, Miller, L 1990 The relationship between recurrent clinical pain and pain threshold in children. Adv Pain Res Ther $15: 333-340$

9. Walco, GA, Varni, JW, Ilowite, NT 1992 Cognitive-behavioral pain management in children with juvenile rheumatoid arthritis. Pediatrics 89:1075-1079

10. Varni, JW, Thompson, KL, Hanson, V 1987 The Varni/Thompson Pediatric Pain Questionnaire: I. Chronic musculoskeletal pain in juvenile rheumatoid arthritis. Pain 28:27-38

11. Ilowite, NT, Walco, GA 1991 Assessment of pain in children with juvenile rheumatoid arthritis: Relation between pain intensity and degree of joint inflammation. Ann Rheum Dis 51:343-346

12. Lovell, DJ, Walco, GA 1989 Pain associated with juvenile rheumatoid arthritis. Pediatr Clin North Am 36:1015-1027

13. Varni, JW, Wilcox, KT, Hanson, V, Brik, R 1988 Chronic musculoskeletal pain and functional status in juvenile theumatoid arthritis: An empirical model. Pain 32:1-7

14. Savedra, M, Gibsons, P, Tesler, M, Ward, J, Wegner, C 1982 How do children describe pain? A tentative assessment. Pain 14:95-104

15. Melzack, R 1975 The McGill Pain Questionnaire: major properties and scoring methods. Pain 1:277-299

16. Abu-Saad, H 1984 Assessing children's responses to pain. Pain 19:162-171

17. Abu-Saad, H 1990 Toward the development of an instrument to assess pain in children: Dutch study. Adv Pain Res Ther 15:101-106

18. Abu-Saad, H, Kroonen, E, Halfens, R 1991 On the development of a multidimensional Dutch pain assessment tool for children. Pain 43:249-256

19. Abu-Saad, H, Pool, H, Tulkens, B 1994 Further validity testing of the Abu-Saad Pediatric Pain Assessment Tool. J Adv Nurs 19:1063-1071

20. Abu-Saad, H 1994 Pain in children: Developing a program of research. Disabil Rehabil 16:45-50

21. Vandvik, IH, Eckblad, G 1990 Relationship between pain, disease severity and psychosocial function in patients with juvenile chronic arthritis. Scand J Rheumatol 19:295-302

22. Rapoff, MA, Lindsley, CB, Purviance, MR 1991 The validity and reliability of parental ratings of disease activity in juvenile rheumatoid arthritis. Arthritis Care Res 4:136-139 